\title{
Ku Band Rotary Joint Design for SNG Vehicles
}

\author{
Hamid TORPI ${ }^{1}$, Salih Mehmed BOSTAN ${ }^{2,3}$ \\ ${ }^{1}$ Dept. of Electronics and Communication Engineering, Yildiz Technical University, Istanbul, Turkey \\ ${ }^{2}$ PROFEN Comm and Tech Serv. Inc., Istanbul, Turkey \\ ${ }^{3}$ Dept. of Electrical Engineering, The Pennsylvania State University, University Park, USA
}

torpi@yildiz.edu.tr, sbostan@profen.com

\begin{abstract}
A wideband I-type rectangular waveguide rotary joint $(R J)$ is designed, simulated and built. It has an excellent performance over the whole Ku Band (10.7-14.5 GHz) where the return loss is less than $-23 \mathrm{~dB}$ at its highest and the insertion loss is below $0.4 \mathrm{~dB}$. The rotary joint is specifically designed for satellite news gathering (SNG) vehicles providing elevation and azimuthal movement to the antenna and matching polarization when it is needed at the feed. It can also be used in other high power microwave applications, where rotation ability of the antenna is a must during the transmission such as radars.
\end{abstract}

\section{Keywords}

Ku-band, rotary joint, ridge waveguide, SNG vehicle, quarter-wave transformer

\section{Introduction}

Traditionally there are two solutions for guided electromagnetic wave transmission in microwave communication. One solution is to carry the RF signal through coaxial cable and the other one is to guide the wave using waveguides. For the applications where high power transmission and low loss are needed, waveguides provide the best solution. High power signals are guided by commercial WR-75 waveguides in a $\mathrm{Ku}-\mathrm{B}$ and front-end system where WR-75 is a waveguide flange standard that is defined by Electronic Industries Alliance (EIA). Rigid waveguides have been widely used in satellite communication applications, however most of the antenna systems in these applications require full rotation ability without causing any performance degradation and rigid waveguides restrict the movement of the antenna system. Providing the ability of rotation in either elevation or azimuthal direction, a bearing system must be implemented between two waveguide structures. Additionally ensuring circular rotation, a rectangular to coaxial waveguide transition is needed and the device that ensures such mobility is known as rotary joint in the literature. A rotary joint is basically a transition from rectangular waveguide to a coaxial or circular waveguide and then to another rectangular waveguide as longitudinal cross section can be seen in Fig. 1. Inevitably mismatches occur at both junctions, however most of the ro- tary joints are required to turn $360^{\circ}$ around, providing low loss without any interruption during the transmission. $\mathrm{Ku}-$ band rotary joints become significant especially in SNG vehicles where usually three different Rotary joints are needed in each system. Two of them are used to change azimuth and elevation angles and another one is used for polarization correction. Although some applications use flexible waveguides for polarization correction, this causes unusual loss in the system especially after normal wear and tear. The joints for elevation and azimuth control must perform over the transmit frequency band of 13.75 to $14.5 \mathrm{GHz}$. The one for polarization correction should cover the whole Ku-Band. Commonly, $\mathrm{Ku}$ band Rotary joints are designed for transmit band, 13.75 to $14.5 \mathrm{GHz}$ noting that 10.7 to $12.75 \mathrm{GHz}$ is the receive band for Ku band applications. In this work, the rotary joing covers the whole $\mathrm{Ku}$-Band and mechanically constructed in such a way that it could be used as a joint for all three purposes.

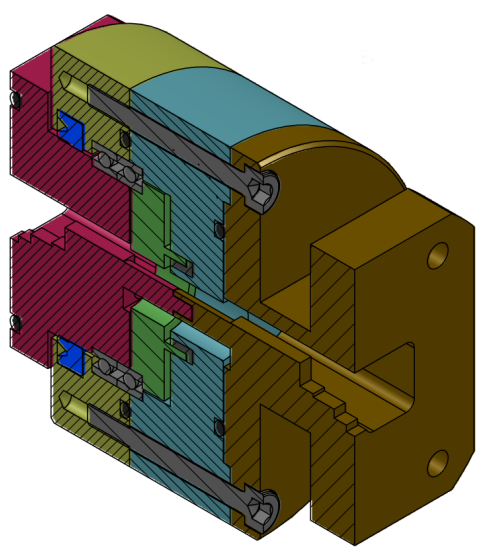

Fig. 1. 3D CAD drawing of the rotary joint.

\subsection{Literature Review}

Design and development of rotary joints have been reported in [1-16]. A single channel RJ presented in [1] consists of two septum polarizers. This RJ is designed to provide return loss of $-15 \mathrm{~dB}$, insertion loss of max. $-0.8 \mathrm{~dB}$ and the isolation less than $-17 \mathrm{~dB}$ in the frequency range $35-$ $41 \mathrm{GHz}$. A compact, $2.3 \lambda_{g}$, single channel RJ operating at $35.0 \mathrm{GHz}$ is presented in [2]. It consists of two identical $\mathrm{TE}_{01}$ mode converters, clasping each other by a bearing. The RJ handled up to a peak input power of $210 \mathrm{~W}$ with a 
duty cycle of $18 \%$. In [3], a U-style single channel waveguide RJ containing a rectangular waveguide $\mathrm{TE}_{10}$ mode to circular waveguide $\mathrm{TM}_{01}$ mode converter is described where return loss is less than $-35 \mathrm{~dB}$ over the $6 \%$ of the Ka-band and return loss is less than $-25 \mathrm{~dB}$ over $10 \%$ of the Kaband. In [4], it is shown that incorporating ridge-waveguide sections, a single-channel waveguide RJ can be designed, which simultaneously provides high power handling capability up to peak power of $250 \mathrm{~kW}$. In [5], full wave analysis of non-contacting RJ choke design is elaborated. Analysis is summarized for the possibilities including linearly polarized $\mathrm{TM}_{01}$ and/or $\mathrm{TE}_{01}$ modes in circular waveguide, circulary polarized $\mathrm{TE}_{11}$ modes in circular waveguide, or TEM modes in coaxial waveguide. A simple experimental procedure to match and to tune the 'door-knob' type microwave coupler that excites $\mathrm{TM}_{01}$ mode in circular waveguide from a rectangular waveguide has been presented in [6]. Some Rotary joints designed to transmit multiple channels. References in [7], [8] and [12-15] report on such rotary joints. Coaxial to ridged waveguide transition is used for the broad-band rotary joint in [9] and the VSWR is less than 1.7 between 0.85 $\mathrm{GHz}$ to $2.7 \mathrm{GHz}$. A high-power single channel waveguide RJ is described in [10], where 1:16 waveguide power divider is used to generate $\mathrm{TE}_{01}$ mode in the circular waveguide. A four step binomial impedance transformer is used to convert from the one-half $\mathrm{E}$ dimension output of the splitters to the full E input of the next two splitters. These transformers were tested at a power of $1.4 \mathrm{MW}$ across $10 \%$ bandwidth without reaching breakdown with a maximum VSWR of 1.15 . Tomiyasu, [11], built an annular rotating joint that permits multiple stacking to provide a number of channels with the help of directional couplers and E-plane joints. A dual channel RJ based on the excitation of circularly symmetric $\mathrm{TM}_{01}$ and $\mathrm{TE}_{01}$ modes in a circular waveguide is described in [12]. The RJ reported in [13], has insertion loss between 0.7 and $1.6 \mathrm{~dB}$ over the $26-40 \mathrm{GHz}$ band and $S_{22}$ is below $-10 \mathrm{~dB}$ over the $26-40 \mathrm{GHz}$ band, except $34.5 \mathrm{GHz}$, where it punctually reaches $-8 \mathrm{~dB}$. In [14], a general design method for $\mathrm{N}$-channel RJ is introduced. They have designed a six channel RJ by using transition between concentric coaxial lines and double-ridged waveguides. Detailed choke design for coaxial waveguides are presented in [15],[16]. In [16] Ka band rotary joint is designed with additional physical capability which can carry $2 \mathrm{~kg}$ antenna but the band width is only $1.5 \mathrm{Ghz}$.

\section{Design Procedure}

In this section, design goals and theoretical justification of the rotary joint will be given.

\subsection{Design Parameters}

Although choke design is essential for rotary joints, in this design physical short is preferred since choke works ideally just for one frequency. Detailed choke design for coaxial waveguides is presented in [15]. At the beginning it was as- sumed that at the coaxial waveguide junction, wall currents pass through without any performance degradation due to the fact that normal components of the current density vector is continuous across the junction so that EM field will not be disturbed.

The bearing system of the $\mathrm{RJ}$ is assumed as a continuous coaxial waveguide. All materials are assumed as PEC. Other noteworthy aspects of the rotary joint design include:

- Rotary joint's expected power capacity. Inner and outer radii of coaxial waveguide are related to that power.

- Impedance matching network design to match rectangular waveguide to coaxial waveguide using ridged waveguides.

Keeping the aforementioned points in mind, the design goals are given below for the rotary joint.

- Operating frequency: $10.7 \mathrm{GHz}-14.5 \mathrm{GHz}$

- First port: WR-75 rectangular waveguide, $a$ : $19.05 \mathrm{~mm}$, $b$ : $9.525 \mathrm{~mm}$ ( $a$ : $0.75 \mathrm{in}, b: 0.375 \mathrm{in})$

- Second port: WR-75 rectangular waveguide $a$ : $19.05 \mathrm{~mm}, b$ : $9.525 \mathrm{~mm}$ ( $a$ : $0.75 \mathrm{i}, b: 0.375 \mathrm{in})$

- Return loss: <-23 dB

- Insertion loss: $<0.4 \mathrm{~dB}$

- Power handling capacity: $1000 \mathrm{~W}$

\subsection{Theoretical Background}

In the dominant $\mathrm{TE}_{10}$ mode, wave impedance of WR-75 waveguide is given by

$$
Z_{\omega}=\frac{n_{0}}{\sqrt{1-\left(\frac{f_{c}}{f}\right)^{2}}} .
$$

It must be noted that impedance of a rigid waveguide is frequency dependent. As shown in Fig. 2 the wave impedance of coaxial waveguide is also frequency dependent. The incident RF signal in WR-75 side is dominant $\mathrm{TE}_{10}$ mode. As mentioned before, coaxial waveguide is used in the rotating section where the dominant $\mathrm{TE}_{10}$ mode is converted to the circular $\mathrm{TE}_{11}$ mode.

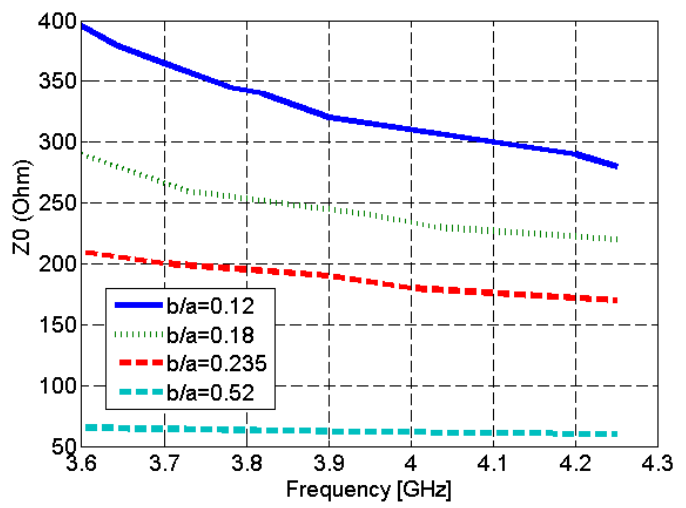

Fig. 2. Characteristic impedance of the $\mathrm{TE}_{11}$ mode in coaxial waveguide. 


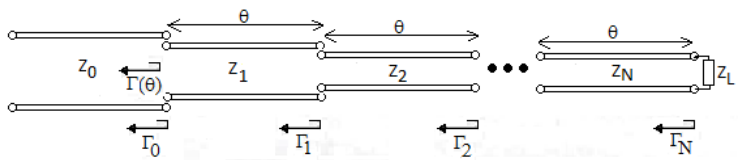

Fig. 3. Multiple quarter-wave transformer structure.

Our aim is to carry the incident signal through RJ ensuring the rotation with reasonably low reflection and insertion loss, which are as known as $S_{11}$ and $S_{12}$ respectively in the nomenclature. This is a well-known wide band impedance matching problem between the rectangular waveguide and coaxial waveguide junction, noting that rotary joint is a reciprocal device. Wave impedances of both waveguides are frequency dependent as it can be inferred from (1) and Fig. 2, however, referring to Fig. 2 again, the wave impedance of the coaxial waveguide approaches to a constant where the inner $(a)$ and the outer $(b)$ radius is 0.52 for the given frequency band. Although Fig. 2 does not include our target frequency band, it is clear that when $b / a$ ratio approaches to 0.5 , the impedance of the waveguide does not change with frequency and it converges to $50 \Omega$. Due to that fact, $b / a$ ratio of the rotary joint is chosen to be 0.52 to achieve a broadband design. Impedance matching between rectangular and coaxial waveguide, is provided by $\mathrm{N}-1$ quarter wave transformers as shown in Fig. 3. The length $\theta_{N}$ of each section must be an odd factor of quarter wavelength and impedance $Z_{n}$ of each section must be found. $Z_{N}$ is taken approximately $50 \Omega$ which represents the coaxial waveguide's impedance that will be chosen for $b / a=0.5$ as in Fig. 2, and $Z_{0}$ represents WR-75 waveguide's impedance.

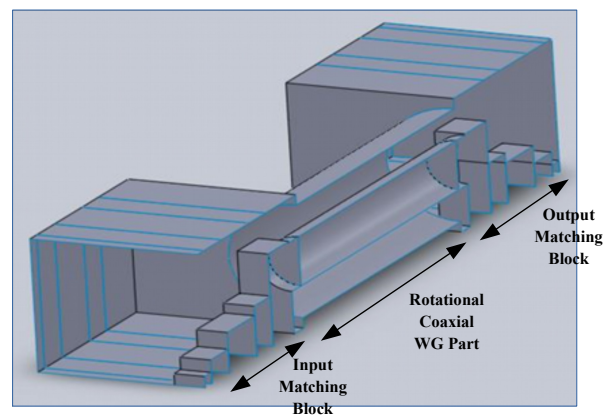

Fig. 4. WR-75 to coaxial waveguide transition - longitudinal cross section.

At the beginning of the simulation process this impedance $\left(Z_{0}\right)$ value is calculated at the middle of the $\mathrm{Ku}$ Band (12.42 GHz). N-1 waveguide sections are realized by using ridge waveguide as shown in Fig. 4 which is also known as ladder transition. The height of the ladders (ridges) will provide requested impedances [9]. According to the theory of small reflections [17], the input reflection coefficient is defined as

$$
\Gamma(\theta)=A \sum_{n=0}^{N} C_{n}^{N} e^{-2 j n \theta},
$$

$$
\Gamma(\theta) \approx \Gamma_{0}+\Gamma_{1} e^{-2 j \theta}+\Gamma_{2} e^{-4 j \theta}+\ldots+\Gamma_{N} e^{-2 j N \theta},
$$

where

$$
\Gamma_{n}=\frac{Z_{n+1}-Z_{n}}{Z_{n+1}+Z_{n}}, \Gamma_{N}=\frac{\left(Z_{L}-Z_{N}\right)}{Z_{L}+Z_{N}} .
$$

These results are useful when all $Z_{n}$ increase or decrease monotonically across the transformer and $Z_{L}$ is real which implies that $\Omega_{n}$ will be real with the same sign. Reflection coefficient of the adjacent junctions is small and increasing the number of transmission line section helps to reduce input reflection coefficient. This theory is known as the theory of small reflections and it is described briefly in (3) and (4). The input reflection coefficient of this transformer is given in (3). If the reflection coefficients at the junctions are selected as a function of Chebyshev polynomial coefficient, the transformer is called as Chebyshev transformer [17]. These reflection coefficients can also be selected as a function of binomial polynomials where such a transformer is called as binomial transformer which is also known as maximally flat transformer. Once the reflection coefficient is selected then impedance of the quarter wave sections could be calculated using (4).

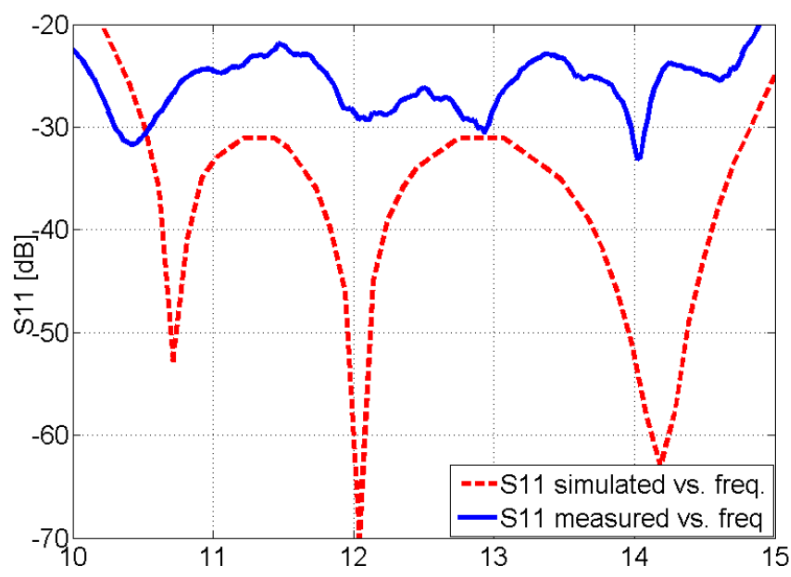

Fig. 5. Simulated and measured return loss results versus frequency.

In the initial design, $\Gamma_{0}$ to $\Gamma_{N}$ coefficients were selected as a function of Chebyshev polynomial coefficients. Chebyshev transformer's impedance values $Z_{1}$ to $Z_{N-1}$ are calculated from (4). Impedance of a rectangular double ridge waveguide is given by [18];

$$
\begin{gathered}
Z=\frac{\pi n_{0}}{\sin \theta_{2}+\left(\frac{d}{b}\right)\left[\frac{B}{Y_{01}}+\tan \frac{\theta_{1}}{2}\right] \cos \theta_{2}}\left(\frac{b}{a}\right)\left(\frac{d}{b}\right)\left(\frac{a}{\lambda_{c}}\right), \\
\theta_{1}=\pi\left(1-\frac{s}{a}\right)\left(\frac{a}{\lambda_{c}}\right), \theta_{2}=\pi\left(\frac{s}{a}\right)\left(\frac{a}{\lambda_{c}}\right),
\end{gathered}
$$

where $B / Y_{01}$ stands in for step discontinuity on sides of the ridge and could be approximated as follows from [19],

$$
\frac{B}{Y_{01}} \approx 4\left(\frac{b}{a}\right)\left(\frac{a}{\lambda_{c}}\right) \ln \operatorname{cosec}\left(\frac{\pi d}{2 b}\right) .
$$

More details on ridge waveguides can be found in [20]. 
As a starting point for the optimization, the aforementioned parameters are used as initial values. Simulation and optimization of the rotary joint is realized by WASP-NET EM simulation software. In addition to avoid electrical breakdown at high power levels, appropriate shortest distance is taken into account.

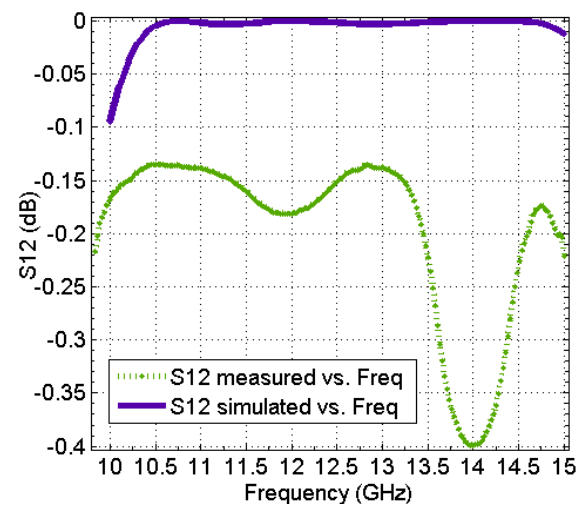

Fig. 6. Simulated and measured insertion loss results versus frequency.

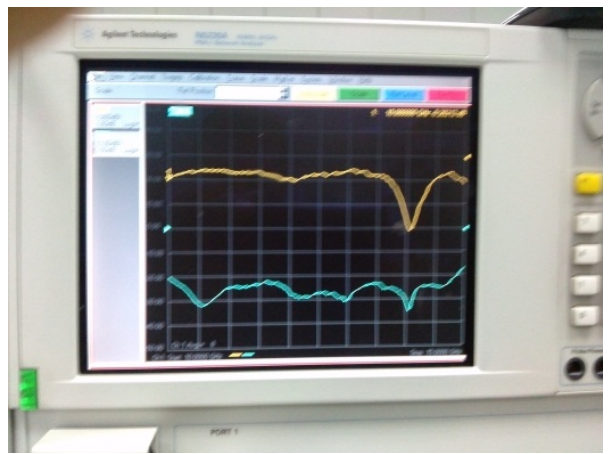

Fig. 7. Measured insertion loss and return loss of the fabricated rotary joint.

\section{Simulation and Test Results}

Fig. 5 and Fig. 6 show the measured and simulated results for return loss and insertion loss respectively. Over the whole band $(10.7 \mathrm{GHz}-14.5 \mathrm{GHz})$ return loss is below $-23 \mathrm{~dB}$ and insertion loss is below $0.4 \mathrm{~dB}$. In Fig. 6, it can be easily deduced that insertion loss is less than $0.2 \mathrm{~dB}$ which means $95 \%$ of input power passes through rotary joint without any loss for $80 \%$ of the whole KU band. Between $13.5-14.5 \mathrm{GHz}$ insertion loss exceeds $0.2 \mathrm{~dB}$ and reaches its maximum punctually at $14 \mathrm{GHz}$ which is $0.4 \mathrm{~dB}$ that means $90 \%$ of input power passes RJ without any loss. These results are in line with the design goal given in Sec. 2.1. A technical drawing for the bearing system is given in Fig. 1. RF test setup for the manufactured rotary joint is shown in Fig. 8.

\section{Conclusion}

A wide band (over 30\%) rotary joint that covers the whole $\mathrm{Ku}$ band is designed, simulated, built and tested. The rotary joint could be used for polarization correction, elevational and azimuthal direction purposes in a satellite news gathering (SNG) vehicle. The initial impedance matching design was based on the theory of small reflections. The CAD software, WASP-NET, was then used to optimize the dimensions. As shown in Fig. 5 and Fig. 6, the simulation results exceeded the design goals. 6061 aluminum alloy was used for producing the prototype and no other optimization, such as silver coating, was applied to the rotary joint. Although a tolerance analysis was carried out before the manufacturing process, the measured results showed some differences with the simulated ones. These differences may be due to the assumption of perfect electric conducting (PEC) material in simulation, imperfections occured in the milling process and the bearing discontinuites in the rotating section of the rotary joint.

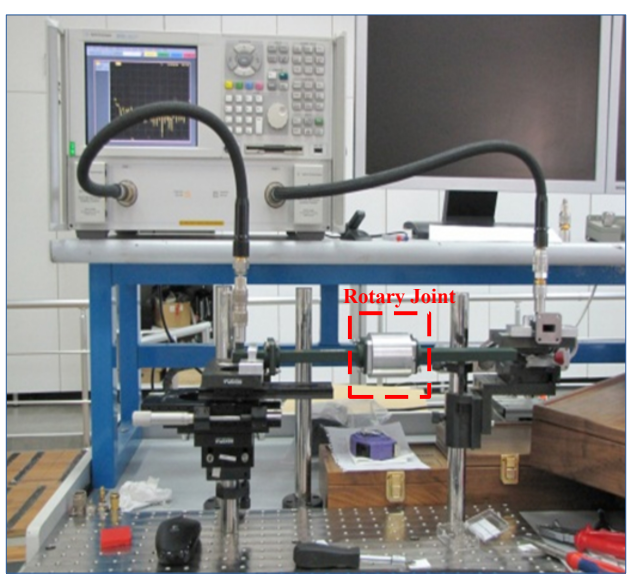

Fig. 8. Measurement setup of the fabricated rotary joint.

\section{Acknowledgments}

The authors would like to thank Onder Havuzlu, Hasan Karagul, Nuri Hacicavusolu, Rizki Tekay, Gurer Danisan and Bahattin Turetken from Scientific and Technological Research Council of Turkey for their invaluable supports and to Dr. E. Arvas of Syracuse University for his invaluable advices. This project is supported by Ministry of Science, Industry \& Technology and PROFEN Comm. Tech. \& Serv. Inc.

\section{References}

[1] KAIDEN, M., KIMURA, K., OGAWA, H., et al. Septum polarizer for Ka-band H-shaped rotary joint. Journal of Infrared, Millimeter and Terahertz Waves, 2009, vol. 30, p. 727-737. DOI: 10.1007/s10762009-9491-9

[2] CHANG, T. H., YU, B. R. High-power millimeter-wave rotary joint for radar applications. In 34th Internatinal Conference on Infrared, Millimeter, and Terahertz Waves (IRMMW-THz). Busan (Souh Korea), 2009. DOI: 10.1109/ICIMW.2009.5325680 
[3] ABRAMOV, V. I., PARK, H.-J., KIM, D.-H., LEE, T.-H. U-style rotary joint with $\mathrm{E}_{01}$ mode for millimeter waves. 2004 IEEE MTT$S$ International Microwave Symposium Digest. Fort Worth (USA), 2004, p. 1879-1882. DOI: 10.1109/MWSYM.2004.1338974

[4] RAMBABU, K, BORNEMANN, J. Compact single channel rotary joint using ridged waveguide sections for phase adjustment. IEEE Transactions on Microwave Theory and Techniques, 2003, vol. 51, no. 8, p. 1982-1986. DOI: 10.1109/TMTT.2003.815269

[5] McNAMARA, D.A., HILDEBRAND, L.T. Fullwave analysis of noncontacting rotary joint choke sections using the generalized scattering matrix (GSM) approach. IEE Proceedings - Microwaves, Antennas and Propagation, 2003, vol. 150, no. 1, p. 5-9. DOI: 10.1049/ipmap:20030438

[6] FRANCO, M. A. R., SERRAO, V. A., FUHRMANN, C., HERDADE, S. B. A simple procedure for impedance matching and tuning of microwave couplers for an electron linear accelerator. IEEE Transactions on Microwave Theory and Techniques, 2001, vol. 49, no. 3, p. 562-564. DOI: 10.1109/22.910565

[7] WOODWARD, O. M. A dual-channel rotary joint for high average power operation. IEEE Transactions on Microwave Theory and Techniques, 1971, vol. 18, no. 12, p. 1072-1077. DOI: 10.1109/TMTT.1970.1127413

[8] BORONSKI, S. A multichannel waveguide rotating joint. Microwaves, 1965, vol. 8, p. 102-105.

[9] MUENZER, P. J. Broadbanding coaxial-to-ridged-wave-guide transitions. Microwaves, 1964, vol. 3, p. 92-96.

[10] SMITH, P. H., MONGOLD, G. H. A high-power rotary waveguide joint. IEEE Transactions on Microwave Theory and Techniques, 1964, vol. 12, p. 55-58. DOI: 10.1109/TMTT.1964.1125751

[11] TOMIYASU, K. A new annular waveguide rotary joint. Proceedings of the IRE, 1956, vol. 44, no. 4, p. 548-553. DOI: 10.1109/JRPROC.1956.274939

[12] RAABE, H. A rotary joint for two microwave transmission channels of the same frequency band. IRE Transactions on Microwave Theory and Techniques, 1952, vol. PGAP-4, p. 136-136. DOI: 10.1109/TPGAP.1952.237413

[13] ZÜRCHER, J.-F. A 6.5-50 GHz battery-powered compact rotary joint for polarization elipticity measurement. Microwave and $O p$ tical Technology Letters, 2011, vol. 53, no. 2, p. 375-379. DOI: 10.1002/mop. 25692

[14] MALlAHZADEH, A., AHMADABADI, H. Design of N-channel rotary joint using curved double ridged waveguide and concentric coaxial lines. Applied Computational Electromagnetics Society Journal, 2012, vol. 27, no. 1, p. 50-58.

[15] KING, H. E. Broad-band coaxial choke coupling design. IRE Transactions on Microwave Theory and Techniques, 1960, vol. 8, no. 2, p. 132-135. DOI: 10.1109/TMTT.1960.1124711

[16] YEVDOKYMOV, A., KRYZHANOVSKIY, V., PAZYNIN, V., et al. Ka-band waveguide rotary joint. IET Microwaves, Antennas \& Propagation, 2013, vol. 7, no. 5, p. 365-369. DOI:10.1049/ietmap.2012.0326
[17] POZAR, D. M. Microwave Engineering. 3rd ed. NY, USA: John Wiley \& Sons Inc, 2010.

[18] HOEFER, W. J. R., BURTON, M. N. Analytical expressions for the parameters of finned and ridged waveguides. In IEEE MTT-S International Microwave Symposium Digest. 1982, p. 311-313. DOI: 10.1109/MWSYM.1982.1130702

[19] MARCUVITZ, N. Waveguide Handbook. Boston Technical Publishers, 1964.

[20] HELSZAJN, J. Ridge Waveguides and Passive Microwave Components. IET, 2000. ISBN: 978-0852967942

[21] UHER, J., BORNEMANN, J., ROSENBERG, U. Waveguide Components for Antenna Feed Systems: Theory and CAD. Artech House, 1993. ISBN: $978-0890065822$

[22] BOSTAN, S. M. KU Band Waveguide Component Design for SNG Vehicles. MSc Thesis. Istanbul (Turkey): Yıldız Technical University, 2011.

\section{About the Authors...}

Hamid TORPI was born in Stuttgart, Germany, in 1967. He received the B.S. degree in Electronics and Communication Engineering and the M.S. degree, both from Yildiz University, Istanbul, Turkey, in 1988 and 1991, respectively, and the Ph.D. degree from Yildiz Technical University (YTU) in 1997. He is currently an Assistant Professor at YTU. His research interests include neural network applications of microwave circuits and devices, antennas, and design of microwave circuits and devices. Dr. Torpi is a recipient of science awards from Turkish Scientific and Technical Research Council and YTU.

Salih Mehmed BOSTAN was born in Uskudar, Istanbul, in 1985. He received the B.S. degree in Electronics and Communication Engineering from Haliç University in 2009 and M.S. degree in Electronics and Communication Engineering from Yıldız Technical University (YTU) in 2011. He also worked as an R\&D Engineer in PROFEN Comm. \& Tech. Serv. Inc. between September 2009 and August 2012 $\mathrm{He}$ is currently $\mathrm{PhD}$ student in Electrical Engineering at The Pennsylvania State University, University Park. His research interests include waveguides, high power microwave systems, ionospheric heating, ionospheric plasma instabilities, software defined radar. 